\section{Factors For Developing Students 'Critical Thinking Skills In The Process Of Teaching Mathematics}

\section{Murod Barakaev}

Associate Professor of Tashkent State Pedagogical University, PhD, Uzbekistan

Abdivali Shamshiev

Associate Professor of Jizzakh State Pedagogical Institute, PhD, Uzbekistan

\section{Sherzod Shodiev}

Basic doctoral student of Navoi State Pedagogical Institute Uzbekistan

\section{Sayfiddin Baxramov}

Associate Professor of the National University of Uzbekistan, PhD, Uzbekistan

\section{Zebo G'iyosova}

Independent researcher of Jizzakh State Pedagogical Institute, Uzbekistan
G OPEN ACCEsS

The American Journal of Applied Sciences

JULY 2020

Page No.: 28-34

Volume-II Issue-VII

PUBLISHED: 30 JULY 2020

www.usajournalshub.com/inde x.php/tajas

Copyright: Original content from this work may be used under the terms of the Creative Commons Attribution 4.0 licence.

Abstract. This article reveals the need to develop critical thinking in students in the process of teaching mathematics, the opportunities for its development.

Keywords: Information, thinking, reasoning, critical thinking, critical thinking development, critical thinking development technology, stages of its implementation. 


\section{Introduction}

In today's world where the flow of information is increasing day by day, one of the main goals of education is to effectively accept students and thereby develop their critical thinking. Achieving this leads to the formation of the ability of students to evaluate independently in the process of working with new information, looking at each of them with deep reflection and criticism, and based on personal imagination. Thinking for students in a modern educational environment:

- comparing different perspectives and approaches;

- should be aimed at giving the opportunity to express and prove their point of view in a reasonable way, based on the laws of evidence and science, their own observations, their own or others' experience.

Achieving the above will help each person to develop intellectually and spiritually, to be able to work with information, to think critically and creatively. Nowadays, the development of critical thinking in students is based on the creative collaboration of student and teacher, the student's analytical approach to any material, which is characterized not by memorizing the material, but by identifying the problem and looking for its solution in the study of each theoretical or practical material.

Hence, critical thinking is the ability of students to analyze information based on a logical and personal-psychological approach, which allows them to apply the results in both standard and non-standard situations. This process is characterized by openness to new ideas, a tendency to accept them.

\section{THE MAIN FINDINGS AND RESULTS}

In general, the formation of critical thinking requires the following conditions in the educational process: Creating an environment for students to form critical thinking and gain some experience on it; giving students the opportunity to think by accepting a variety of ideas and opinions expressed by them during the lesson; to allow students to take an active part in the lesson process and to ensure that no one laughs at them when they express opinions or put forward ideas; the teacher is able to convince each student that each student has the ability to think critically and to develop it, and to appreciate it when students express critical thinking, and so on.

It is known from the course of psychology that each person forms his own ideas, thoughts and beliefs independently. In doing so, it is effective for him to achieve the formation of his personal opinion through independent research and in-depth analysis of what he has learned. It is important to note that critical thinking does not have to have an unnatural or unique meaning. Because in this he has the right to accept the ideas and views 
of others as our own. So, critical thinking is independent thinking.

It is known that the knowledge acquired by a person forms in them the motivation necessary for critical thinking and serves as a basis for the formation and development of critical thinking. As a result, through critical thinking: a unique individual approach to the process of assimilation and perception of the acquired knowledge and information is formed; knowledge is continuously acquired consciously and the efficiency and quality of

their acquisition increases. From the above, it is clear that information is not the end product of critical thinking, but serves as a basic stage.

If critical thinking is focused on solving real problems derived from students 'personal lives, they will express the problems based on their personal life experiences and then master the problem-solving skills given using the knowledge and opportunities acquired in school. This further increases their chances of acquiring knowledge while being understood. So, critical thinking starts with asking questions and identifying problems that need to be solved.

Experience has shown that every person who is able to think critically can find a personal solution in the process of solving problems encountered in different situations and strengthen it with convincing and well-founded evidence. At the same time, the results of critical thinking will be more effective and meaningful if the arguments on the points of view are also reasonably accepted or denied. The most interesting thing about this is that the critical thinker tends to prove that the solution he or she chooses is more logically correct and reasonable than other solutions. It is very difficult to change the mind of a thinking person with high evidence and proofs, and he can resist the opinions that are accepted by the majority. As a result of discussion, debate, and exchange of views, the individual approach becomes clearer and deeper.

In this process, each student working in small groups will have the opportunity to solve more complex problems in the process of forming their own personality. Also, in the process of effective communication, important qualities such as listening to others, tolerance, ability to respond to one's own point of view are formed, and the problem of bringing the learning process closer to real life becomes an effective solution. This feature of critical thinking allows us to conclude that the critical thinker is ready to live in today's changing world.

If we consider the formation and development of critical thinking in this way as a separate technology, then with the help of this technology will increase the chances of solving the following important issues: Striving for learning: increased interest in the learning process and active mastering of learning materials; be able to receive information correctly: develop the ability to independently analyze and evaluate information of any complexity; ability to feel social responsibility: formation of responsibility for communicative skills and knowledge. When learning about this technology, the acquisition of knowledge is significantly improved, because it is focused not only on memorization, but also on the creative process of understanding the world, the identification of the problem and the search 
for its solution. It is advisable to use the following interactive methods in the development of critical thinking: working in small groups, modeling of educational material, role-playing games, discussions, methods of individual, group projects. Appropriate and effective use of these interactive methods: ensures the conscious mastery of the studied material, increases students' interest in the subject, develops social and individual skills. The critical thinking development technology we mentioned above is implemented in the following three stages:

Organizational phase. This stage determines the level of importance of the knowledge that students need to acquire on the topic being studied, and thus arouses interest in the study of this topic. Therefore, it is at this stage that the objectives of teaching and learning the material are determined.

1. The stage of understanding the new learning material (new information, idea, concept) being studied. At this stage, the student first gets acquainted with the content of the text on the subject (here the concept of "text" is considered in a broad sense, it can consist of reading new material in the textbook, understanding the terms of the problem, listening to the teacher).

2. The stage of thinking, that is, the stage of meditation. At this stage, the student tries to understand the new learning material and forms his own opinion on it, his attitude to the newly learned learning material.

It is important to strictly follow the above steps in each lesson, because the thinking process is manifested in these stages, and this feature of TFR technology increases the possibilities of expanding its scope of application. The application of TFR technology is more efficient when the project method is used. This is because the teacher goes through all the stages of knowledge acquisition together with the students and he becomes a direct participant in this process. In this process, it is advisable for the teacher to provide information about the sources of information or to direct students' opinions in the direction in question in order to help students to independently research and work on new learning materials. In this case, students will find a solution to the problem using the knowledge they have acquired independently from additional sources and will have sufficiently realistic and realistic, i.e., external and internal results. In this case, if the external result can be seen, understood, applied in practice, the internal result is considered as an activity and practical experience (intellectual property of the student) that generalizes knowledge and skills Research and pedagogical experience show that the use of TFR technology in general secondary schools, starting from the course of mathematics, creates opportunities to involve students in project activities.

1-for example. Study the topic "Dividing the whole into parts (parts)."

Implementing the study of the topic by solving practical problems of the following content plays an important role in achieving the intended goal.

Problem: If the ice cream contains 5 parts water, 2 parts milk fat and 3 parts sugar, how much water, milk fat and sugar will be needed to make one kilogram of ice cream? 
Phase 1: Organizational Phase. Brief description of the problem (such issues can be considered in the study of the subject "Proportion of the number" in primary school)

$\left.\begin{array}{l}\text { Water }-5 \text { parts } \\ \text { Milk fat }-2 \text { parts } \\ \text { Sugar - } 3 \text { parts }\end{array}\right\} 1 \mathrm{~kg}$

Let's describe the scheme as follows?

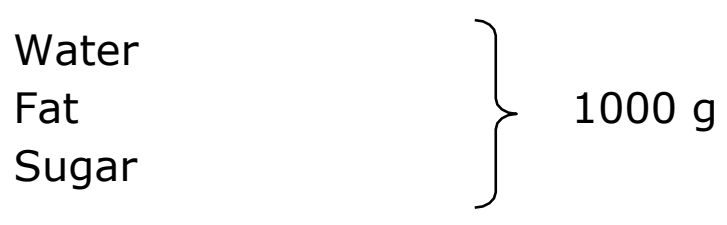

The second case is the most convenient way to solve the problem.

Phase 2 . The stage of understanding the new learning material (new information, idea, concept) being studied. If this problem is solved in the traditional way, that is, by going from simple to complex, then high efficiency will be achieved.

It is advisable to have the following questions for discussion in solving the problem: Which of the questions given in the textbook fits this model? State the terms of several issues that apply to this model.

One number is twice as large as the second, but three times smaller than the third. The sum of the numbers is 27 . Find these numbers? Is this an issue of fragmentation? Prove it!

Create a model independently and determine the algorithm for solving the problem.

Step 3. Thinking, that is, the stage of meditation. At this stage, it is advisable to ask the following question:

Two jars contain 5 liters of milk. When 1 liter of milk was added to one jar, the amount of milk in it was 2 times more than in the other jar. How much milk was in each jar? Is this an issue of fragmentation? Think about how to solve it.

Addressing issues of this content can be considered as the beginning of work on the project. In this case, the project development work is created separately by the teacher and the student. Let's look at an example of such a project below.

Project: Create a set of questions based on the principle given in the table below:

An issue created by the reader 
We can describe this project as follows:

practice-oriented (by main type of activity);

mono-project (in the field of subject-matter);

individual (according to the number of project participants);

long-term (depending on the duration of the project).

A similar project activity can be organized in the 9th grade Algebra course on "Trigonometric Functions and Their Graphs". At the same time, students under the guidance of the teacher "Problems of practical content. Trigonometric functions and their graphs".

Example 2 In the school course "Fundamentals of Algebra and Analysis" you can also look at "Solving trigonometric equations".

Step 1. Organizational phase. At this stage, students are initially given test assignments (pre-prepared by the teacher) that focus on each of them to be active. Therefore, the lesson should begin with individual work, and these individual work should consist not of testing students' knowledge, but of "self-checking" tasks.

In this case, the student solves the equation " $\sin x+\cos x=1$ " on the topic

There are 6 different methods. Students who identify the situation will then be asked a variety of questions on the topic. Phase 2 . The stage of understanding the new learning material (new information, idea, concept) being studied. In this case, the equations of equal strength formed by the same form transformations using different trigonometric formulas for the equation $\sin x+\cos x=1$ are analyzed.

Step 3. Thinking, that is, the stage of meditation.

At this stage: the method of solving it for each equation is written in the table;

independently solve difficult equations on the part of students using "manuals" and comparing them with the solutions on the board;

students who solve the problem on solutions are asked questions.

Of course, achieving this will, firstly, increase students' interest in learning mathematics, secondly, form and further develop their critical thinking skills, thirdly, they will gain knowledge as a result of the above, and fourthly, their interest in learning other subjects will increase.

In this case, the role of the teacher is unique, and only if he can think critically enough, he will be able to teach, which is his main task, even in the most difficult situations.

\section{CONCLUSION}


In short, in the teaching of mathematics in the context of modern education, the achievement of the development of critical thinking in students - stimulates their desire to acquire knowledge consciously. Increasing their independent knowledge leads to the formation of skills, which in turn allows each student to enjoy the work he is doing. All of this serves as a key factor in ensuring that today's educational goals are achieved.

\section{REFERENCES}

1. David Cluster. What is critical thinking. Weekly "Russian language" of the publishing house "First of September", No. 29, 2002.

2. Barakaev M. and b. Development of critical thinking as a factor of conscious learning // Proceedings of the Republican scientific-practical conference "Problems and solutions of vocational education of specific sciences", part 2, Navoi, 2018, p.42-44.

3. Butenko A.V., Khodos E.A. Critical thinking: method, theory, practice. Textbookmethod. allowance. M .: Miros, 2002.

tledge,2009.-1 